\title{
A Nursing Innovation Workshop to Improve Clinical Nurses' Innovation Ability: a Quasi-experimental Study
}

\section{Limei Gao}

[AK] Southern Medical University Affiliated Nanhai Hospital

Qiaocong Lu

[AK] Southern Medical University Affiliated Nanhai Hospital

Jiefen Ou

[AK] Southern Medical University Affiliated Nanhai Hospital

Xiangchuan Hou

[AK] Southern Medical University Affiliated Nanhai Hospital

Mingzhu Wang ( $\square$ mingzhugoodluck@hotmail.com )

[AK] Southern Medical University Affiliated Nanhai Hospital https://orcid.org/0000-0001-9855-6741

\section{Research article}

Keywords: innovation, workshop, nurses, quasi-experimental

Posted Date: August 3rd, 2020

DOI: https://doi.org/10.21203/rs.3.rs-48052/v1

License: (c) (i) This work is licensed under a Creative Commons Attribution 4.0 International License. Read Full License 


\section{Abstract}

Background: Currently, the innovation ability of nurses in China is at a medium to low level. Most studies focus on nurses' innovation ability and its influencing factors, while few interventional studies consider how to improve nurses' innovation ability. The aim of the study is to explore the effects of nursing innovation workshops in improving clinical nurses' innovation ability.

Methods: This Quasi-experimental study was conducted in a tertiary hospital of Guangdong. Thirty-seven recruited nurses participated in a nursing innovation workshop for half a year. Questionnaire data were collected on nurses' selfrated innovation ability and research ability before the training and 3 months after finishing the training.

Results: Nurses' self-rated innovation ability and research ability improved significantly after the training $(P<0.001)$.

Conclusions: A nursing innovation workshop is an effective and feasible teaching method that can promote the generation of innovative thinking and improve the innovative ability of nurses.

\section{Background}

In response to the rapid development and progress of science and technology, hospitals have promoted healthcare innovations to develop highly efficient and economical patient-centred care environments [1]. As a key force in healthcare services, nurses must constantly innovate to keep pace with the health industry and to improve the quality of care [2]. Innovation is "the design, invention, development, and/or implementation of new or altered products, services, systems, organizational structures, or business models for the purpose of creating new value for customers and financial returns for the firm" [3]. The American Nurses Association (ANA) defined nursing innovations as putting new thoughts or existing ideas into the practice of new methods [3]. The ANA noted that solving the complex problems of clinical practice requires innovative solutions and methods. Yan et al[4] defined nurses' innovation ability as the ability to actively seek and develop new methods, new technologies and new tools to promote health, prevent diseases and improve the quality of care of patients and the ability to apply innovation to work through teamwork and reasonable support channels. This study adopts this definition, which includes four elements: innovation subject, innovation process, innovation environment and pressure and innovative products [4].

In most health systems across the world, nurses provide up to $80 \%$ of primary health care [5]. Nurses are critical thinkers on the front lines of care delivery who often innovate by identifying more efficient processes or repurposing items for alternate uses; they are therefore uniquely positioned to improve clinical practice through such ideas [6, 7]. Fostering innovative nursing ability could improve medical service quality, increase job productivity, improve the effectiveness of treatment, reduce healthcare costs while satisfying the needs of patients, improve the effectiveness of care services, improve access to healthcare services and simplify the process involved in delivering such services [1, 811].

However, the level of innovation ability of nurses in China and abroad differs. Polster et al. [12] investigated 217 clinically registered nurses and found that $90.3 \%$ of them had good innovative ability, while the research of Stilgenbauer et al. [13] showed that nursing managers and clinical nursing experts generally had a high level of innovative abilities and behaviours compared with general clinical nurses. Compared to these studies, there is an obvious shortage of nursing innovation talent in China. Zhang et al. [14] conducted a survey of 620 nurses in a thirdlevel first-class hospital in Harbin in 2017. These authors found that the overall score of nurses' innovation behaviour was low. Similarly, Chen et al. [15] investigated the innovation ability of 1260 clinical nurses in Zhengzhou in 2019. 
Nurses' position, professional title, working years, leadership and job satisfaction as well as the organizational innovation climate were the main factors affecting their innovation ability [16-18].

Scholars have developed different strategies to address the lagging innovation ability of clinical nurses[19, 20]., including providing education and training on innovation processes and lean techniques, scheduling time for teams to brainstorm and solve problems together, providing resources such as financial, information, personal, and emotional support, and actively adjusting the talent cultivation model to meet the current need for innovative nursing talent for the development of healthcare services [6, 21-24]. While these contextual factors are important, innovations will not occur unless basic knowledge of innovation is provided to motivated and competent nurses, especially those who lack previous innovation experience [22].

A workshop is a method for solving problems that is attended by individuals (between 25 and 40 people) who are in the same scientific or technical field [25] We report on an intervention study of a nursing innovation workshop in clinical practice education. It is a collaborative and constructive teaching organization that involves attracting participation, provoking thinking, and promoting interaction and growth [26]. The methods of case analysis, role play, group sharing; group discussion, brainstorming, teacher commenting and behaviour training have been widely used in foreign countries [27-29]. In nursing, the concept of the workshop is still in its infancy. Currently, workshops mainly focus on nursing education, nurse training and clinical nursing $[26,29,30]$.

Therefore, the aim of this study was to conduct nursing innovation training through a teaching organization form of a workshop and to explore its influence on the innovation ability of clinical nurses. We hypothesized that nurses who were given the opportunity to participate in the nursing innovation workshop would improve their innovation ability significantly. We further predicted that they would produce more nursing innovations over time.

\section{Methods}

\section{Design, setting and participants}

A quasi-experimental study was conducted at the People's Hospital of Nanhai District, including one group with baseline and follow-up assessment. We used this design because it was feasible and ethical to conduct according to the authors' real working environment.

Clinical nurses who met the criteria were recruited for this study. The inclusion criteria were registered nurses who (1) had worked for more than 1 year in the authors' hospital, (2) had a bachelor's degree or above as their final degree and a passion for nursing innovation, and (3) filled in the recruitment form completely and clearly. The exclusion criteria were as follows: (1) registered nurses who did not work in the hospital during the investigation period (including those who went out for further study and sick leave) and (2) registered nurses who were participating in other teaching programmes or studies. According to the literature review, we found that the sample size of the workshop should be between 25 and 40 people [25,30]. Given the specific implementation plan of this research workshop, the number of participants in the workshop was determined to be 30 . Considering that there might be a $20 \%$ attrition rate during the programme, the final sample size was calculated to be 36 . Ultimately, 37 participants were enrolled in the study. All of the participants completed the study.

Ethical approval of this study was granted by the Ethics Committee of the People's Hospital of Nanhai District Foshan, Guangdong. The nurses received information about the study and voluntary participation and provided informed consent before data collection. Furthermore, the participants were informed that they had the right to withdraw from the study at any time without any explanations or consequences. 


\section{Intervention}

A nursing innovation workshop was administered by a research team which was composed of 10 members, including one director and one deputy director of the nursing department, one ward head nurse, one research nurse, one clinical evidence-based nursing tutor, one director of nursing education and 4 education nurses from different wards. Their responsibilities were to establish a workshop team, recruit members, conduct research on innovation, formulate training content for scientific research and innovation, and contact relevant experts to organize and implement learning on relevant topics.

According to the recruitment situation, the group was divided into 4 groups of 8-10 people. The innovation team leader was selected on the basis of the investigation of the research team and the recommendation of the innovation team members. The team leader was required to have an intermediate or above professional title, obtain one or more patents, and have solid knowledge of innovation and scientific research capabilities with a rigorous and pragmatic academic attitude and good communication skills. The responsibilities of the team leader were to lead the members to implement innovation and offer consultation to the members.

Aiming to understand the participants' training need, we designed a questionnaire to investigate their training motivation, training methods, experience with scientific research innovation and relevant factors affecting training (Table 1) according to the literature review [31, 32]. Then, we developed a specific learning course (including the theoretical training and practical training) through the analysis of the current needs of nurses.

Theoretical training involved 12 hours of courses (once a week for two hours) that were mainly taught and guided by domestically and provincially experienced innovation experts. The content involved current innovation policies, the training of innovative thinking, patent development, application and transformation and some relevant typical innovation cases to encourage the nurses' participation.

Practical training was accomplished with the help and support of the innovation group leaders. The main content involved conducting innovations to solve clinical problems and ultimately completing the production of product prototypes. At the end of the theoretical course, members of each group were required to brainstorm, choose their own topics, conduct a product demand survey, and conduct innovative design and resource retrieval to realize their creative ideas. The members of each group were given different roles and responsibilities to maximize the function of the team. After finishing the innovative protocol, they submitted it to the research team for discussion, optimization and amendment. Finally, there was a competition for patented products to enhance the participants' innovative spirit after the completion of practical training.

\section{Outcome measures}

The primary outcome in this study was clinical nurses' innovation ability, assessed using the Scale of Clinical Nursing Staff Innovation Ability [4],which was divided into 4 dimensions with 41 items, including the nurses' innovation subjects (17 items), innovation process (12 items), innovation environment and pressure (7 items) and innovative products (5 items) [4]. This scale was a five-point ordinal scale (1-5) with a maximum score of 205 points; the higher the score, the higher the nurse's innovation ability [4]. Relevant studies showed that the Cronbach's coefficient of the scale was 0.938 , and the Cronbach's coefficient of each dimension was $0.825 \sim 0.876[4,15]$. The preliminary experiment of this study showed that the Cronbach's coefficient of the scale was 0.857 .

The second outcome in this study was clinical nurses' research ability, assessed using The Scale of Nursing Scientific Research Ability, which was designed by Yin-he Pan [33] from Shanxi Medical University in China. This scale has 6 dimensions and 30 items, including the ability to generate research ideas (3 items), the ability to search and review 
literature ( 5 items), the ability to design a research protocol ( 5 items), the ability to conduct research ( 6 items), the ability to analyse research data and material (5 items), and the ability to write a research report (6 items) [33]. The scale was a five-point ordinal scale (0-4) with a maximum score of 120 points; a higher score represents a higher level of research ability [33]. Relevant studies show that the scale has good reliability [34]. In our study, the Cronbach's coefficient of research ability was 0.983 .

The time points for assessment were at zero (pre-intervetion) and 3 months (follow up). Participants were assessed by completing the questionnaires through an online anonymous star thematic survey questionnaire. In addition, baseline characteristics were assessed through a sociodemographic questionnaire, including gender, age, foundational education, highest academic credential, professional title, length of service, nursing duties and department.

\section{Data Analysis}

Statistical analyses were conducted using IBM SPSS 22.0.0 statistical software, and the test level was a=0.05. The general data of clinical nurses were described by frequency, percentage, mean and standard deviation. The clinical nurses' scores for innovation ability and scientific research ability were described by the mean and standard deviation. A paired $t$ test was used for measurement before and after intervention.

\section{Results}

The demographic characteristics of the participants are listed in Table 1. The sample included 37 nurses with a mean age of 38 years, ranging from 27 to 48 years. The majority were female (94.6\%), had no previous higher education (67.6\%) and had a bachelor's degree or above through on-the-job training (100\%). Most of them were from internal medicine and surgical departments, were supervisor nurses, and had been working in the hospital for more than 10 years $(64.9 \%)$ with special nursing duties, such as nurse leaders and specialist nurses (81.1\%). Most of the nurses decided to participate in this workshop to improve their innovation ability (35.2\%). Case analysis (94.6\%), group discussion and sharing (81.1\%), brainstorming (86.4\%) and expert comments (86.4\%) were their favourite training methods. Finally, most of them had no previous patents (89.2\%), and the main influencing factor was a lack of innovation knowledge (81.1\%).

Before and 3 months after the training, there were statistically significant differences in the total scores of clinical nurses' innovation ability ( $t=25.07, P<0.001)$, innovation subjects $(t=12.99, P<0.001)$, innovation process $(t=14.57$, $P<0.001)$, innovation environment and pressure $(t=11.99, P<0.001)$, and innovative products $(t=11.85, P<0.001)($ Table 2).

Before and 3 months after the training, the total score of clinical nurses' scientific research ability $(Z=-5.31, P<0.001)$, ability to generate research ideas $(t=10.48, P<0.001)$, ability to search and review literature $(t=9.24, P<0.001)$, ability to design research protocol ( $t=7.21, P<0.001)$, ability to conduct research ( $t=11.05, P<0.001)$, ability to analyse research data and material $(t=8.09, P<0.001)$, and ability to write a research report $(t=7.95, P<0.001)$ showed statistically significant differences (Table 3).

\section{Discussion}

The results showed that most of the clinical nurses who participated in this study had a bachelor's degree or above, medium professional titles and special responsibilities and had no previous innovation experience [15]; furthermore, $40.54 \%$ of head nurses participated in this training, consistent with Chen et al. [15]. Although some foreign nursing schools have attempted to establish "nursing innovation" to combine nursing professional education with innovation 
$[9,27]$, innovation in clinical nursing education in China is still in the initial state [31]. Key nursing staff members, such as nurse leaders, were the main participants in the innovation ability training programme, indicating that nursing leaders attached great importance to nursing innovation to help themselves learn to be more creative[13, 19, 35]. As the key power of nursing management and promoters of nursing tasks, key nursing staff had excellent theoretical knowledge and professional skills and were responsible for the nursing quality and nursing safety [36]. Many key nursing staff had a highly professional sense of mission, high levels of job involvement and successful innovation through on-the-job innovation training [16]. In addition, the nurse leader participants in this study could provide good examples to inspire creativity and could provide education to empower staff to use creative thinking techniques to solve problems in practice $[17,19,36,37]$.

The nursing innovation workshop brought together nurses with a passion for innovation. The workshop was established and guided by tutors with rich innovation experience. It provided an open, democratic and inclusive organizational culture that embraced innovativeness and empowered nurses to advance new ideas, enhance interaction, improve their self-confidence and self-esteem and exert an obvious positive influence on individual innovation behaviour [37-39]

Innovation ability refers to the comprehensive ability of people to make use of accumulated knowledge and experience, process and rebuild through scientific thinking, and produce new knowledge, new ideas, new methods and new results [40]. The results of this study showed that after training in the nursing innovation workshop, the scores of nurses' innovation ability and scientific research ability were significantly higher than before the training $(P<0.05)$. These results were similar to the research results of Jiang Yan [31] and Zhang Ziyun [32], indicating that the nursing innovation workshop training was conducive to improving nurses' innovation ability. The training content, which was based on the core elements of innovation ability and the actual training needs of clinical nurses removed the constraints of the traditional thinking mode, emphasized the stimulation of members' independent thinking and learning ability [32] and opened up a new way of nursing innovation education and training.

After 12 hours of participation in the workshop with different themes in theoretical training, participants could recognize the concept of nursing innovation and basic steps. In the practice courses, the participants could give full play to their subjective initiatives to identify problems in nursing practice and use creative thinking strategies to create prototypes of the devices they envisioned with the help of the workshop members [11]. In addition, the workshop adopted diverse training methods, such as participatory methods and case discussions, to encourage team members to actively participate in thinking and discussing questions to promote the participants' learning and cultivate innovative thinking [29]. Moreover, a WeChat group was used to enhance trust, a spirit of inquiry, the value for learning, and resource support for innovativeness and experimentation [19] to further enrich the innovative atmosphere. Finally, we identified four group leaders with rich innovation experience to guide the members in conducting research on the transformation of clinical problems into innovative topics. This helped to improve the participants' familiarity with the innovation process as well as their innovative thinking and spirit, thereby improving nurses' innovation practice without practical training guidance and enhancing nurses' confidence and practical ability in nursing innovation [7].

Since this study was the first to conduct a nursing innovation workshop in one district hospital, the research scheme had high feasibility and operability and was popular with the participants, but it also had some limitations. First, only one hospital was included and the number of participants was small, which could increase the risk of selection bias. Second, the design was quasi-experimental; therefore, the results cannot be entirely attributed to the effect of the interventions due to the lack of a control group, which constrains the generalization of the conclusions. Therefore, this study needs to be further verified in more hospitals and among more nurses. 


\section{Conclusion}

The present results indicate that nursing innovation workshops can improve clinical nurses' innovation ability and provide a new way of thinking and a new method for teaching about innovation. With regard to the other variables, we found that innovative creative thinking can promote the development of scientific research thinking to improve clinical nurses' research ability. Further interventions designed as randomized control trials with larger groups from different levels of hospitals would be useful to confirm the present findings on the effect of nursing innovation workshops on the cultivation of nurses' innovation ability.

\section{Abbreviations}

ANA: American Nurses Association

\section{Declarations}

\section{Ethical approval}

The study was approved by the Ethics Committee of the People's Hospital of Nanhai District\Foshan, Guangdong (Ethical review number:2019015).

\section{Consent for publication}

Not applicable

\section{Competing interests}

No conflicts of interest have been declared by the authors.

\section{Funding}

This research was a self-funded project supervised by the Foshan Science and Technology Bureau (Project Number: 1920001000846).

\section{Availability of data and materials}

The data of this study generated and analysed are not publicly available but may be available from the corresponding author on reasonable request.

\section{Author's contributions}

LG: Conceptualization, Methodology, Writing-Original Draft preparation

QL: Conceptualization

$\mathrm{XH}$ : Data Curation, Software, Investigation

JO: Funding acquisition, Data Curation

MW: Conceptualization, Methodolgy, Investigation, Writing-Reviewing and Editing

Statement: All authors have read and approved the manuscript 


\section{References}

1. Weng RH, Chen WP, Huang $\mathrm{CY}$, Hung $\mathrm{CH}$, Hsu CT: Can nurse innovation improve customer perception of service quality and experience? Journal of clinical nursing 2016, 25(13-14):1950-1961.

2. Yan D, Wen F, Li X, Zhang Y: The Relationship Between Psychological Capital and Innovation Behavior in Chinese Nurses. Journal of nursing management 2020, 28(3):471-479.

3. American Nurses Association(ANA). Innovation in Nursing and Healthcare. https://www.nursingworld.org

/practice-policy/innovation-in-nursing\#fni(Accessed 11 April 2020)

4. Yan J, Yang J, Jiang Y, Zhao M, Wang H: Development of Nurse Innovation Ability Scale and its reliability and validity testing. Chinese journal of nursing 2018, 53(10):1213-1217.

5. Shahsavari Isfahani S, Hosseini MA, Fallahi Khoshknab M, Peyrovi H, Khanke HR: Nurses' creativity: advantage or disadvantage. Iranian Red Crescent medical journal 2015, 17(2):e20895.

6. Croke L: Perioperative nurses can change clinical practice through innovation. AORN journal 2019, 110(1):P5.

7. Timmermans $O$, Van Linge R, Van Petegem P, Van Rompaey B, Denekens J: Team learning and innovation in nursing, a review of the literature. Nurse education today 2012, 32(1):65-70.

8. Whyte A: Innovation improves care. Nursing standard (Royal College of Nursing (Great Britain) : 1987) 2016, 30(48):23-25.

9. Clark E, Webster B: Innovation and its contribution to the scholarship of learning and teaching. Nurse education today 2012, 32(7):729-731.

10. Gardner G, Woollett K, Daly N, Richardson B, Aitken LM: Innovation in clinical learning for the acute hospital environment: nursing grand rounds. Nurse education today 2010, 30(8):737-741.

11. Liu HY, Wang IT, Chen NH, Chao CY: Effect of creativity training on teaching for creativity for nursing faculty in Taiwan: A quasi-experimental study. Nurse education today 2020, 85:104231.

12. Polster D, Villines D: An Exploratory Descriptive Study of Registered Nurse Innovation: Implications for Levels of Adoption. Clinical nurse specialist CNS 2017, 31(1):E1-e9.

13. Stilgenbauer DJ, Fitzpartick JJ: Levels of Innovativeness Among Nurse Leaders in Acute Care Hospitals J Nurs Adm 2019, 49(3):150-155.

14. Zhang $\mathrm{L}$, Wang $\mathrm{H}$ : The relationship between nurses' professional benefit perception and innovation behavior. Chinese Journal of Nursing Research 2015, 29(26):3313-3314.

15. Chen R, Hong X, Zhang H, Niu J, Zhang H, Li Y: The innovation ability and its associated factors among nurses in tertiary hospitals in Zhengzhou. Chinese Nursing Management 2020, 20(1):73-77.

16. Wang Y: Research on the relationship among nursing managers' calling, inclusive leadership, work engagement and innovation behavior. Anhui of China: Anhui Medical University; 2018.

17. Lv M, Zhao H, Zhou Y, Zhuang J, Wang N, Zhang S: The impact of head nurses' authentic leadership on nurses' innovative behavior. Chinese Journal of Nursing Administration 2018, 18(10):712-715.

18. Xiang Y, Xiong L: The relationship between transformational leadership and nurse innovation behavior. Chinese Journal of Nursing Research 2018, 32(14):2179-2182.

19. Snow F: Creativity and Innovation: An Essential Competency for the Nurse Leader. Nursing administration quarterly 2019, 43(4):306-312.

20. Moore J, Crozier K, Kite K: An action research approach for developing research and innovation in nursing and midwifery practice: building research capacity in one NHS foundation trust. Nurse education today 2012, 
32(1):39-45.

21. Albert NM: Operationalizing a Nursing Innovation Center Within a Health Care System. Nursing administration quarterly 2018, 42(1):43-53.

22. Li-Ying J, Paunova M, Egerod I: Knowledge sharing behaviour and intensive care nurse innovation: the moderating role of control of care quality. Journal of nursing management 2016, 24(7):943-953.

23. Sun Y, Ye Z: The influence of the structural empowerment and psychological empowerment on nurses' innovative behaviors. Chinese Journal of Nursing 2015, 50(5):556-560.

24. He X, Shen L, Wang X, Wang X, Hu D, Niu J: The influence of out-of-hospital training on the nursing cooperation, clinical nursing and research innovation ability of primary hospital nurses. Chinese Journal of Nursing Research 2019, 33(3):498-500.

25. Yazdani M, Sabetian G, Ra'ofi S, Roudgari A, Feizi M: A comparative study of teaching clinical guideline for prevention of ventilator-associated pneumonia in two ways: face-to-face and workshop training on the knowledge and practice of nurses in the intensive care unit. Journal of advances in medical education \& professionalism 2015, 3(2):68-71.

26. Zhou M: Effect of comprehensive case of emergency nursing care workshop on clinical decision making ability in undergraduate nursing students. Zhengzhou of China: Zhengzhou University; 2016.

27. Yonge O, Myrick F, Ferguson L: A student evaluation workshop with rural nursing preceptors. Journal for nurses in staff development: JNSD : official journal of the National Nursing Staff Development Organization 2012,

28(3):125-131.

28. Lai HL: Preliminary study of the effects of an educational workshop on therapeutic use of music and aesthetic experience with music in first-line nurses. Nurse education today 2011, 31(8):e63-69.

29. Li IC, Chen YC, Hsu LL, Lin CH, Chrisman NJ: The effects of an educational training workshop for community leaders on self-efficacy of program planning skills and partnerships. J Adv Nurs 2012, 68(3):600-613.

30. Grugnetti AM, Bagnasco A, Rosa F, Sasso L: Effectiveness of a Clinical Skills Workshop for drug-dosage calculation in a nursing program. Nurse education today 2014, 34(4):619-624.

31. Jiang Y, Sun L, Yu Y, Cai C: Effect exploration of innovation ability training for nurses based on CDIO model. Chinese Journal of Nursing Science 2017, 32(16):71-74.

32. Zhang Z, He X, Jiang Y, Wu L, Zhang L, Yan J: Using the ADDLE model of instructional design to teach nursing innovation and effect evaluation. Chinese Journal of Nursing Science 2019, 34(10):73-75.

33. Pan Y, Cheng J: Revise of scientific research ability selfevaluation rating scales of nursing staff. Chinese Journal of Nursing Research 2011, 25(13):1205-1208.

34. Wang M, Xie R, Lu Q, Ou J, Gao L: Determinants of research ability among nurses in a tertiary hospital in China: A cross-sectional survey. Journal of Educational Research and Reviews 2019, 7(10):206-212.

35. White KR, Pillay R, Huang X: Nurse leaders and the innovation competence gap. Nursing outlook 2016, 64(3):255261.

36. Noles K, Barber R, James D, Wingo N: Driving Innovation in Health Care: Clinical Nurse Leader Role. Journal of nursing care quality 2019, 34(4):307-311.

37. Joseph ML: Organizational culture and climate for promoting innovativeness. J Nurs Adm 2015, 45(3):172-178.

38. Syme R, Stiles C: Promoting nursing research and innovation by staff nurses. Applied nursing research : ANR 2012, 25(1):17-24.

39. Zhang L, Liu J: Investigation on influence of organizational innovation atmosphere on nurses' innovation behavior. Chinese Journal of Nursing Research 2017, 31(7):824-826. 
40. Wei X, Zhang Y: Review of theoretical models of nurse innovation behavior. Chinese Journal of Shanghai Nursing 2019, 19(7):53-56.

\section{Tables}




\begin{tabular}{|c|c|c|c|}
\hline Characteristic & $N(\%)$ & Characteristic & $\mathrm{N}(\%)$ \\
\hline Gender & & Education nurses & $5(13.5)$ \\
\hline Male & $2(5.4)$ & Specialist nurses & $4(10.8)$ \\
\hline Female & $35(94.6)$ & No special duties & $7(18.9)$ \\
\hline Age (years) & & Department & \\
\hline $27 \llbracket 30$ & $3(8.1)$ & Internal & $12(32.5)$ \\
\hline $31 \varangle 40$ & $25(67.6)$ & Surgical & $11(29.7)$ \\
\hline $41 \varangle 48$ & $9(24.3)$ & Gynaecology and paediatrics & $4(10.8)$ \\
\hline Foundational education & & Critical care unit & $4(10.8)$ \\
\hline Technical secondary school & $10(27.1)$ & Other & $6(16.2)$ \\
\hline Junior college & $15(40.5)$ & Main training motivation & \\
\hline Bachelor's degree & 12(32.4) & Promotion needs & 12(32.4) \\
\hline Highest academic credential & & Job demand & 12(32.4) \\
\hline Bachelor's degree & $35(94.6)$ & Self-improvement & 13(35.2) \\
\hline Master's degree & $2(5.4)$ & Training methods (multi-select) & \\
\hline Professional title & & Case analysis & $35(94.6)$ \\
\hline Junior nurse & $1(2.7)$ & Role play & $5(13.5)$ \\
\hline Senior nurse & $4(10.8)$ & Group discussion and sharing & $30(81.1)$ \\
\hline Supervisor nurse & $17(46.0)$ & Brainstorm & $32(86.4)$ \\
\hline Associate professor nurse & 13(35.1) & Expert comments & $32(86.4)$ \\
\hline Chief nurse & $2(5.4)$ & Number of patent & \\
\hline Length of service (years) & & 0 & $33(89.2)$ \\
\hline $3 \otimes 10$ & $4(10.8)$ & 1 & $2(5.4)$ \\
\hline $11 \varangle 20$ & $24(64.9)$ & 2 & $2(5.4)$ \\
\hline $21 \llbracket 30$ & $9(24.3)$ & $\begin{array}{l}\text { Innovation influencing factors } \\
\text { (multi-select) }\end{array}$ & \\
\hline Nursing duties & & Busy work & $30(81.1)$ \\
\hline Head nurse & $15(40.6)$ & Lack of innovation knowledge & $30(81.1)$ \\
\hline Nurse group leader & $6(16.2)$ & Reward factor deficiency & $15(40.6)$ \\
\hline
\end{tabular}




\begin{tabular}{|c|c|c|c|c|c|}
\hline $\begin{array}{l}\text { Measurement } \\
\text { factors }\end{array}$ & $\begin{array}{l}\text { Innovation } \\
\text { subjects }\end{array}$ & $\begin{array}{l}\text { Innovation } \\
\text { process }\end{array}$ & $\begin{array}{l}\text { Innovation environment } \\
\text { and pressure }\end{array}$ & $\begin{array}{l}\text { Innovative } \\
\text { products }\end{array}$ & $\begin{array}{l}\text { Total score of } \\
\text { innovation ability }\end{array}$ \\
\hline Baseline & $60.24 \pm 7.39$ & $42.14 \pm 4.61$ & $23.89 \pm 3.45$ & $13.03 \pm 4.34$ & $139.30 \pm 15.42$ \\
\hline Follow-up & $64.46 \pm 7.93$ & $45.86 \pm 4.69$ & $27.32 \pm 3.60$ & $15.57 \pm 4.83$ & $153.22 \pm 16.51$ \\
\hline$\triangle$ Score & $4.22 \pm 1.97$ & $3.73 \pm 1.56$ & $3.43 \pm 1.74$ & $2.54 \pm 1.30$ & $13.92 \pm 3.38$ \\
\hline t value & 12.99 & 14.57 & 11.99 & 11.85 & 25.07 \\
\hline$P$ value & $\bowtie 0.001$ & $\llbracket 0.001$ & $\varangle 0.001$ & $凶 0.001$ & $\llbracket 0.001$ \\
\hline
\end{tabular}

$\triangle$ Score: Change between baseline and follow-up

\begin{tabular}{|c|c|c|c|c|c|c|c|}
\hline $\begin{array}{l}\text { Measurement } \\
\text { factors }\end{array}$ & $\begin{array}{l}\text { Ability to } \\
\text { generate } \\
\text { research } \\
\text { ideas }\end{array}$ & $\begin{array}{l}\text { Ability to } \\
\text { search and } \\
\text { review } \\
\text { literature }\end{array}$ & $\begin{array}{l}\text { Ability to } \\
\text { design } \\
\text { research } \\
\text { protocol }\end{array}$ & $\begin{array}{l}\text { Ability to } \\
\text { conduct } \\
\text { research }\end{array}$ & $\begin{array}{l}\text { Ability to } \\
\text { analyse } \\
\text { research } \\
\text { data and } \\
\text { material }\end{array}$ & $\begin{array}{l}\text { Ability to } \\
\text { write a } \\
\text { research } \\
\text { report }\end{array}$ & $\begin{array}{l}\text { Total score } \\
\text { of scientific } \\
\text { research } \\
\text { ability }\end{array}$ \\
\hline Baseline & $6.03 \pm 1.76$ & $8.38 \pm 2.70$ & $6.68 \pm 3.17$ & $8.41 \pm 3.32$ & $5.14 \pm 3.16$ & $8.86 \pm 3.49$ & $43.49 \pm 13.30$ \\
\hline Follow-up & $7.97 \pm 1.94$ & $12.00 \pm 3.87$ & $9.43 \pm 4.29$ & $11.65 \pm 3.96$ & $7.59 \pm 3.80$ & $12.03 \pm 4.32$ & $60.68 \pm 18.44$ \\
\hline$\triangle$ Score & $1.95 \pm 1.13$ & $3.62 \pm 2.38$ & $2.76 \pm 2.33$ & $3.24 \pm 1.79$ & $2.46 \pm 1.85$ & $3.16 \pm 2.42$ & $17.19 \pm 8.41$ \\
\hline$t / Z$ value & $10.48^{a}$ & $9.24^{a}$ & $7.21^{a}$ & $11.05^{a}$ & $8.09^{a}$ & $7.95^{a}$ & $-5.31^{b}$ \\
\hline$P$ value & $\varangle 0.001$ & $₫ 0.001$ & $\varangle 0.001$ & $\llbracket 0.001$ & $\varangle 0.001$ & $₫ 0.001$ & $\varangle 0.001$ \\
\hline
\end{tabular}

$\triangle$ Score: Change between baseline and follow-up

${ }^{a}$ paired $t$ test

${ }^{\mathrm{b}}$ Wilcoxon signed rank test 